\title{
Teaching Engagement of Senior High School Teachers in Batangas Province
}

\author{
Wilson T. Ojales ${ }^{1 *}$, Joshua Mark Sandigo D. De Ramos ${ }^{2}$ \\ ${ }^{1,2}$ Department of Education, Taal National High School, Batangas, Philippines
}

\begin{abstract}
Senior High School (SHS) teachers are at the forefront of providing quality and innovative education for students who would either enter the world of work or pursue tertiary education. Therefore, their commitment and dedication to their craft should be carefully delved into, and one of the dimensions where they manifest such attributes in the teaching profession is the level of their engagement in the delivery of instruction. Hence, this study was conducted in order to assess the engagement of selected SHS teachers in Batangas Province during the academic year 20192020. It specifically covered the extent of teachers' engagement as characterized by their vigor, dedication and absorption, and explored on the factors that contribute to their engagement as to school policy, school culture, teacher empowerment, and interpersonal relationship. It also analyzed how teaching engagement is manifested in terms of cognitive, physical, and emotional domains and looked into the sources of burnout in teaching, with the end view of proposing effective measures to foster effective teaching engagement. The descriptive method of research was utilized in the study with the use of a questionnaire as the main data gathering instrument. Gathered data were further enriched through the focus group discussion and interviews. Respondents included 85 school heads and 322 SHS teachers in the province of Batangas. The statistical tools utilized were weighted mean, ranking, and t-test. Results from the findings revealed that teachers manifest moderate engagement in vigor, dedication, and absorption. It was also revealed that school policy and administration moderately contribute to teachers' engagement, while school culture and interpersonal relationships greatly contribute to their engagement. On the other hand, school heads assessed that teacher empowerment greatly contributes to engagement, while teachers claimed that this factor affects their engagement moderately. Comparison on the assessments between the two groups of respondents revealed they concurred in vigor, absorption, teacher empowerment, and interpersonal relationship, but differed in their assessments on dedication and school culture. Moreover, work overload issues, absence of an awards and recognition system, and big class sizes were found to be the primary sources of teachers' burnout.
\end{abstract}

Keywords: Senior high school, Work engagement.

\section{Introduction}

Education inevitably shapes the nation and transcends socioeconomic boundaries, affecting various sectors such as the government, agriculture, business, industries, and even the academia itself. This only manifests the diversity and active role of education in nation-building, which means quality education is not only a primary tool towards individual growth, but more importantly, a prerequisite to communal unity and a principal factor for countrywide success. The commitment to quality education thus requires strengthening inputs, processes, and evaluation of outcomes to ensure that students are well equipped after graduation. Despite innovations in the academe and the proliferation of modern learning platforms as a product of advancements in technology, one concept remains true - that education delivered in schools is a vital instrument in ensuring the acquisition of competencies and values that one needs in order to thrive in local and global workplaces. It may be seen as a rigorous process, given its cyclical reforms and the multifarious academic considerations, but the present and future generations are dependent on it in order to survive and prosper in their personal life and professional career. In order to do this, schools need to ensure that teachers are actively and continuously engaged, since teacher quality is seen as the most important school-related factor influencing student achievement (Rice, 2003). They have to be empowered, adequately recruited, well-trained, professionally qualified, motivated, and supported within well-resourced, efficient and effectively governed systems. Engaged teachers help achieve quality education that fosters creativity and knowledge, and ensures the acquisition of the foundational skills of literacy and numeracy, as well as analytical, problem solving and other high-level cognitive, interpersonal and social skills. However, rapid and massive changes in the school system formulate different scenarios in the Philippines. Many schools and school teachers are perceived to be resistant to such changes, but some simply accept, adapt, and look forward to the positive transformations promised by these innovations. The Department of Education (DepEd) in particular has been responding to the relevant needs of the Filipino learners, and the department expects teachers to adjust to the unavoidable modifications in the system so as not be left behind by the neighboring countries. This is true across grade and year levels, but is more prominent in the Senior High School level, which is relatively new in the country. Senior High School (SHS) teachers are at the forefront of providing quality and innovative education and hence should exemplify the 21 st century skills towards providing the expected outcomes in the present time. However, like any other professionals, they too have aspirations and goals in life that motivate them to fully harness their varied

*Corresponding author: wilson.ojales001@deped.gov.ph 
inherent skills and expertise. They engage in the field of teaching not only because of its noble purpose of educating the future leaders and builders of the land, but also to defray their daily expenses and serve as a means to socialize, which are the pragmatic reasons for enduring the rigors of the job. Teaching engagement is therefore one necessary aspect that needs to be delved into, given the vital role it plays in ensuring the attainment of institutional objectives and student outcomes. Their vigor, or their stamina and robustness in teaching, as well as their dedication to their craft, must be well considered in order to ascertain effective delivery of instruction. An engaged teacher also manifests clear absorptive capacity to be able to adapt to the changes in student behavior and in the trends of a specific field of disciplines. Teachers' engagement is also correlated to the different policies in school. Sometimes teachers find it hard to cope with the varied school, while the school culture also directly influences teachers' engagement. The teachers have different orientations and professional belief systems, which may lead to disagreement or communication breakdown. Having a sound school culture is an advantage to teachers performing their varied tasks, while a poor school culture can be detrimental to overall school performance. The researcher, being a SHS teacher, has many observations and experiences relative to the manner by which SHS teachers sustain work engagement and motivation. In school, also there are a number of factors that contribute to one's commitment to the profession, and others have apparently been affected in negative ways, which led to the conceptualization of the study. This was anchored on the idea that the SHS program is vital in preparing $\mathrm{K}$ to 12 graduates who are ready to either take on the world of work or pursue tertiary education. The SHS teachers' teaching engagement best supports this endeavor. This is shaped through activities and practices evident in curriculum, instruction, and assessment, aided by various administrative and academic support services. Ultimately, the study aimed to foster better teacher engagement by proposing measures to achieve this purpose. This may assist DepEd, especially the SHS program, to emphasize the influence of teachers' engagement and work habits in ensuring the success of curricular offerings. Through this, teachers will have a better perspective of how working with effectiveness and efficiency in the workplace contributes to personal and institutional success.

\section{Objectives of the Study}

This study aimed to assess the engagement of Senior High School teachers in the province of Batangas, with the end view of proposing measures to foster more effective teaching engagement. Specifically, it sought answers to the following questions:

1. As assessed by school heads and teachers themselves, to what extent are they engaged in teaching, characterized by the following?
a) Vigor
b) Dedication
c) Absorption

2. To what extent do the following factors contribute to teachers' engagement?

a) School policy and administration

b) School culture

c) Teacher empowerment

d) Interpersonal relationship

3. How do the assessments by the two groups of respondents compare?

4. How is teaching engagement manifested in the following domains?

a) Cognitive

b) Physical

c) Emotional

5. What are some sources of burnout in teaching?

6. Based on the analysis, what measures to effectively foster teaching engagement may be suggested?

\section{Materials and Methods}

The study utilized a self-constructed questionnaire as the main data gathering instrument. Focus group discussion and interview were also conducted to enrich the findings of the study. A four-part questionnaire was the primary tool used to gather pertinent data. The researcher constructed a questionnaire based on the gained concepts and insights about teaching engagement and other relevant factors. The researcher's personal observations were also considered in its construction. Parts I and II of the questionnaire focused on the respondents' assessment on teaching engagement as to vigor, dedication, and absorption, as well as on the extent of contribution of school policy and administration, school culture, teacher empowerment, and interpersonal relationship to teacher engagement. Part III dealt with the assessment on the extent of manifestation of engagement among teachers as to cognitive, physical, and emotional domains. Part IV concentrated on identifying and evaluating sources of burnout in teaching. Construction. The instrument used was anchored on the statement of the problem, and was based on interviews and readings from related literature covering the concepts on teaching engagement. The first draft was presented to the adviser for comments and suggestions, which were then incorporated into the second draft. After several refinements of the questionnaire items and upon approval of the adviser, several copies of the questionnaire were prepared for the members of the panel for validation. Validation. The researcher was advised to present the draft of the questionnaire to experts in the field for validation. A dry-run to test the validity of the instrument was likewise conducted. Reliability testing was done using Cronbach alpha Test. The results revealed that the questionnaire contained high internal efficiency level of 0.871 , which was higher than the minimum constant value of 0.70 , indicating the instrument was reliable and the options in the questionnaire were appropriate for utilization. Administration. The researcher personally administered the questionnaire to the different senior high schools in Batangas Province. Respondents were informed of the purpose of the study and the need for their honest and objective participation. The researcher retrieved the filled out copies of the questionnaire from the respondents soon after they finished answering the instrument. 
After all the data were tallied and well-accounted for, these were subjected to statistical treatment with the help of the statistician.

\section{Result and Discussion}

1. Extent of teachers' teaching engagement. The study assessed the senior high school teachers' extent of engagement in terms of vigor, dedication, and absorption.

\section{A. Vigor}

As teachers, it is expected that they manifest high levels of energy and mental resilience in the delivery of instruction. They are also expected to show willingness to invest effort in their work and must be persistent in facing academic trials and difficulties in order to show vigor. Based on the assessment by the school heads, teachers were moderately engaged in updating and maintaining records such as learners' progress, as reflected in the highest weighted mean of 3.25. It implies that teachers need to deliberately understand and internalize the significance of keeping students' records and making them updated in terms of students' academic achievement. They also need to understand that keeping students' record is an important duty inherent of being a teacher. Teachers shared during the FGD that maintaining records is a primary tool to update students' learning, which would consequently determine school success. This finding conforms to the idea of Molimaya that effective teachers as transformational leaders contribute a lot in school success. They are record organizers, keepers, classroom supporters, catalysts for change, and lifelong learners. The school heads also assessed that teachers have moderately shown willingness for in-service training opportunities organized within and outside the school, as seen in the weighted mean of 2.92. It means that teachers have expressed limited willingness in the conduct of in-service trainings, and so they need to see the importance of growing professionally by means of attending various trainings and seminars provided by the school. Further, teachers must be able to reflect this willingness because at the end of the day, it is the students who will benefit from their enhanced skills as a result of such trainings. As shared in the interview with teachers, they have expressed that during their supposedly free time, they are still pre-occupied with duties other than teaching. They also shared that they are degree holders and some are pursuing post graduate studies, which for them is enough. This supports the idea of Bauzon that teachers have to update and grow professionally and attend advancement to maintain professionalism at all times. Moreover, the school heads also assessed that teachers were moderately engaged in thinking of going to work right every morning, looking strong and vigorous in doing daily lesson $\log$, and enrolling in graduate program for career advancement. These indicators received the weighted means ranging from 2.73 to 2.70 . This implies that teachers need to have a positive mindset that coming to school is both a responsibility and an obligation. They need to see the beauty of realizing the day's goals by coming to school prepared and having the energy for class. In general, the composite mean of 2.71 revealed that teachers are moderately engaged in teaching relative to vigor. They need to be inspired and mentally prepared for all the possibilities that might happen in and outside the school. As a whole, the composite mean of 2.93 reveals that teachers are moderately engaged in terms of vigor. This suggests that teachers have to be physically and mentally ready in order for them to be more engaged in effectively performing the multifarious tasks assigned to them.

\section{B. Dedication}

Inherent to being a teacher is being dedicated in all undertakings especially in the inherent mandate of being committed and passionate in the teaching profession. Based on the assessment of the school heads, teachers were moderately engaged in seeing that teaching concepts, skills, and values are challenging as indicated in the highest weighted mean of 2.82 . This means that teachers need to become more aware that despite being challenging, teaching these concepts and skills, once learned by the students, are long-lasting and could be retained in the students' mind. Students need to adapt and absorb these concepts to be ready for the future - either for work purposes or for higher education. Participating eagerly in the LACs, FGDs, and meetings to enrich teaching practice was seen to be slightly engaged in by teachers as manifested in the lowest weighted mean of 2.32. This implies that attendance to and participation in professional development training programs and other meetings must one of the priorities of teachers. They have to keep themselves available in such activities to help them improve their teaching prowess. Further, it was also revealed in the FGD that teachers are the ones to benefit the most after having attended these trainings and meetings. However, due to conflict of schedule and other school related matters, some teachers fail to attend even they have that interest to learn more. Overall, the composite mean of 2.62 revealed that teachers were moderately engaged in terms of dedication. They need to be more dedicated in pursuance of all the activities related to school, especially in the pursuit of professional development activities, which would not only benefit them in their career path but ultimately help students by translating these activities to more innovative teaching and assessment strategies.

\section{Absorption}

The engagement of teachers is also characterized by absorption, which allows effortless concentration, a clear mind, as well as a sense of enjoyment and engrossment. Based on the assessment of the school heads, teachers were moderately engaged in sharing experiences related to the content of the lesson useful to the realization of set objectives, as seen in the highest weighted mean of 2.91. This points to the call among teachers to be more realistic in sharing experiences that would help students understand the lesson better. They have to carefully identify approaches that would turn help achieve their objectives. As emphasized by Corpuz, teachers' humor and significant experiences are like magnets in the attainment of the day's lesson for encouragement, moral lessons and students' maturity. As assessed by school heads, teachers were slightly engaged in detaching from classroom structure to engage learners in various activities, and using technology inside the 
classroom for students be more independent as they develop greater skills. These are evident in the weighted means of 2.39 and 2.35 , respectively. These results point to the very essence of teaching profession in relation to facing students in a daily classroom situation. Teachers must be able to plan for teaching activities which may be done beyond the classroom's physical structure. Hence, this also highlights the desire of teachers to utilize technology-based instruction to develop students' skills and abilities.

2. Factors that contribute to teachers' engagement. The study also delved into the extent to which various factors contribute to teachers' engagement relative to school policy and administration, school culture, teacher empowerment, and interpersonal relationship.

\section{School Policy and Administration}

An academic institution's policies, rules and by-laws are significant factors that contribute to teachers' engagement. Based on the assessment made by the school heads, having a vision-mission statement greatly contributed to teachers' engagement as seen in the highest weighted mean of 3.74. This implies that teachers are engaged because they understand the vision, mission, and goals of the school. They also internalize what it means to be part of the school. They are knowledgeable and are aware of how the vision, mission and goals affect their teaching experiences in school. As Thompson reiterated, having pride and sharing the same goals basically attract employees to stay and be productive members of the organization. Having the establishment of the school governing council was assessed to moderately contribute in the engagement of teachers as reflected in the lowest weighted mean of 3.31. This implies that teachers need to understand that having an official governing body or council to establish positive and effective school management is a requirement among schools. They must be able to see the relevance of this council in the actualization of the whole management of schools. As DepEd Order 19 reiterates, it is imperative for teachers to establish governance of the school through constant collaboration with the school governing council and other stakeholders. The composite mean of 3.48 reveals that school policy and administration moderately contribute to the engagement of teachers. This implies the need for teachers to be more aware and better understand how the different school policies work in relation to the development of teachers' engagement.

\section{E. School Culture}

Good attitudes, strong positive behavior, shared values, and willingness to exert considerable effort create effective and productive linkages between and among members of the organization. These constitute school culture, which also influence teacher engagement. Based on the assessment of the school heads, promoting student centered learning greatly contributes to teachers' engagement, as seen in the highest weighted mean of 3.74. This infers that teachers are good lesson designers and can strategize well in providing activities suited to the level of the students. They have wide knowledge on the different strategies that would contribute to effective learning and development. Likewise, school heads assessed that supplementing the no-work, no-pay policy moderately contributed to teachers' engagement, as seen in the lowest weighted mean of 3.06. This implies that teachers, as members of the school community, need to prioritize service above anything else. They have to understand that there will be times when their attendance is required even during holidays or weekends. Being teachers, they are often expected to cooperate and support. However, this does not always sit well with most teachers, which relates to the notion of Caputo that not paying attention to employee's needs and wants is one of the sources why employees tend to lose engagement in the workplace. Generally, the composite mean of 3.51 indicates that school culture greatly contribute teachers' engagement. Hence, the provision of a healthy school culture may directly enhance engagement among teachers, and eventually among members of the academic community. The teachers' assessment also revealed that preserving the school's corporate image to the community and engaging stakeholders in school programs and projects greatly contributed to teachers' engagement. These are evident in the weighted means of 3.58 and 3.54, respectively. This highlights their welcoming spirit to all stakeholders who are invited to attend a certain school activity or program. They know that these stakeholders play a significant role in the fulfillment of the schools' goals. Engaging them in all undertakings is also a way of protecting the good name of the school and organization, which related to Perda's concepts that ensuring that teachers retain the corporate image of the school is vital for autonomy and investment in school's success. As a whole, the composite mean of 3.52 reveals that school culture greatly contributed to teachers' engagement. This means that teachers' engagement is due to the knowledge and understanding of the school culture, and that a positive and healthy school culture would translate to teachers who are more engaged in the profession.

\section{F. Teacher Empowerment}

It is a must for teachers to feel trusted, recognized and given breakthroughs apart from teaching. These empower them and give them more enthusiasm and engagement in the faithful performance of their mandated tasks. Based on the assessment of the school heads, administering a self-constructed test for students greatly contribute to teachers' engagement, as reflected in the highest weighted mean of 3.71. This means that they understand the relevance of designing their own assessment tool to evaluate student learning. They are also aware of the idea that they are free to localize test items anchored on the prescribed DepEd test. School heads also assessed that observing flexibility in implementing instructional curriculum, and managing and supervising curricular and co-curricular progress to support and improve learning greatly contributed to teachers' engagement as seen in the weighted means of 3.58 and 3.57, respectively. This stresses the teachers' important skill of being flexible in implementing instructional curriculum. They are expected to be skilled in providing students with meaningful and challenging activities to facilitate a productive teaching-learning process. Further, 
creative activities are always on teachers' minds to be responsive to 21 st century teaching and learning competencies. This finding conforms to the concept of Zwickert that engaged teachers possess a repertoire of specialized skills required in the delivery of instruction, which plays a crucial role in ensuring the students' academic success. The other items assessed by the school heads to moderately contribute to teacher engagement were receiving justified loads and assignment every semester; coordinating with stakeholders, especially parents, in support to student performance; joining different school programs, projects and teacher organizations; and facilitating learning using appropriate and innovative strategies and classroom management practices. These received weighted means ranging from 3.49 to 3.45 . In their assessment, teachers revealed that publishing articles and researches in journals moderately contribute to their engagement, as it received the lowest weighted mean of 3.09. This implies the perennial challenge for teachers to understand that after conducting researches, it is a must for them to publish these in local and international accredited publications. As revealed in the FGD, teachers have to exert extra effort to publish their researches and establish professional engagement and collaboration with other academicians and researchers. The composite mean of 3.45 indicates that teacher empowerment moderately contributed to teachers' engagement. This means that teachers have to feel more comfortable in fulfilling their task by being entrusted to perform academic related tasks and be part of the decisionmaking process.

\section{G. Interpersonal Relationship}

Teachers are believed to be more engaged once they experience harmonious interpersonal relationships. with their students, fellow teachers, school heads and other stakeholders. This includes dynamic interactions with other members of the school community. Based on the assessment of the school heads, demonstrating positivity to find success in the position, relying on others in some capacity, and being willing to support others all greatly contributed to teachers' engagement as seen in the same weighted mean of 3.65. This means that teachers are optimistic and see things in a positive perspective. They also feel that despite being burdened with lots of paper work, they still find enjoyment serving the position with openness and humility, which is a natural quality of teachers. As Corpuz reiterated, teachers' personality must be natural and genuine, devoid of pretenses and artificiality. They must be consistent, true, and have an authentic passion for teaching. School heads also assessed that applying openness to feedback to yield desirable results and helping keep others' stress level down greatly contributed to teachers' engagement, as manifested in the weighted means of 3.64 and 3.60, respectively. This refers to the importance of staying open-minded in terms of giving feedback, which would have great impact in their teaching career. This also means that being true and honest with constructive comments would lead them to become effective teachers. This means that in the teachers' daily performance of their duties, they always consider the ethical norms and values towards their actions. They know that their actions should be constructive and help others to improve, as encapsulated in RA 7836 as regards the fundamental ethics that reinforces the work of teachers. Further, this also means that teachers have the freedom to clearly express their ideas and opinions and they can communicate with clarity and precision, thus enhancing their level of engagement. The teachers' assessment also revealed that fostering an emotionally supportive learning environment moderately contributed to their engagement as evident in the weighted mean of 3.49. This means that they need to establish a learning environment that is holistically appropriate for the students. At times, they have to consider that students learn best when they are provided with opportunities and chances to explore and generate new knowledge, hence being responsible for their own learning. In general, the composite mean of 3.57 revealed that interpersonal relationship greatly contributed to teachers' engagement. This implies that the manner by which teachers relate with members of the school community greatly influence their level of engagement, echoing the words of Bauzon who emphasized that teachers need to have good interpersonal skills in order to develop positive working relationships inside and outside the school community.

\section{Comparison on the Assessments by the Respondents}

The researcher compared the responses of the school heads and teachers regarding teaching engagement as to vigor, dedication, absorption, and the factors that contribute teaching engagement as to school policy, school culture, teacher empowerment and interpersonal relationship. The $\mathrm{t}-$ test for unequal variances was utilized to test the null hypothesis. Similarities and differences of the responses were also analyzed and interpreted. There was a significant difference in the assessments made by the school heads and the teachers themselves in their engagement in vigor, as shown by the computed t-value of 2.876. Thus, the null hypothesis was rejected since the computed t-value is greater than the tabular value. This indicates that the two groups of respondents had different interactions, exposure and beliefs on the teaching practices, and engagement manifested by the teachers. The teachers must have based their assessment on the daily interactions and practices in their classes, feedback from schools where they are deployed, and colleagues who served as their supervisors. On the other hand, school heads might have based their assessments on their self-perception relative to their knowledge, skills and attitudes towards teacher engagement for more positive results. This means that there is a significant difference in the assessments made by school heads and teachers themselves regarding the extent of contribution of interpersonal relationship to the latter's engagement. From the result, it could be inferred that both school heads and teachers have to extend more support to each other in order to establish a positive connection as they strengthen teacher-to-teacher, teacher-to-student, and teacher-to-learning environment connections through social, spiritual and other relevant activities. These may bring them closer to each other and eventually result to a strong and healthy interpersonal relationship. The higher the interpersonal relationship, the higher the teachers' engagement will be. Based on the analyzed 
data, it can be inferred that the school heads and teachers had similar assessments on teachers' engagement relative to dedication, school policies and administration, and school culture. This could be because they often meet and interact with one another. This helps them to have a meeting of minds, which has led to their similar assessments on the aforementioned indicators.

\section{Manifestation of Engagement in Three Domains}

This study also assessed the extent of manifestation of teacher engagement in the cognitive, physical, and emotional domains. Teachers' engagement is manifested in the cognitive domain. For a teacher to effectively develop their learners, it is important to keep in mind the need for the development of mental skills and the acquisition of new knowledge. Teachers also revealed in their assessment that producing high expectations for every learner to do their best was moderately manifested, as seen in the lowest weighted mean of 2.81. This implies that teachers need to dwell more on the idea that expectations to students should be set on high standards. Teachers must give their inputs to get desirable results from the students. During the interview, teachers affirmed that they always have to believe that their students will produce the best output and be responsible for all their actions and performance. The composite mean of 2.94 indicates that teaching engagement was moderately manifested by teachers in terms of the cognitive domain. This suggests the need for more creative, intellectual activities to better engage teachers in the practice of their profession.

\section{A. Physical Domain}

Teachers' engagement was also analyzed in the physical aspect. Their day-to-day experiences and the multifarious, physical tasks they do give flavor to their teaching engagement. It could be seen from the assessment by the school heads that ensuring safety in the workplace, speaking with a modulated voice and with confidence, and using an appropriate tone in giving instructions were all moderately manifested as seen in the same weighted mean of 3.06. This means that there is a need to provide reliable and convincing strategies for everyone to feel safe inside the school. Moreover, teachers need to ensure every student's attendance in the different school-initiated activities. This is what Payos meant when he posited that the teachers' primary consideration to attain optimum student learning is setting a positive learning environment which is geared to the students' needs and interests. In addition, they have to know that their lesson should be delivered within prescribed period and must allow enough time for students to develop meaningful learning experiences. They also have to know who among their students are struggling and are in need of academic support. This finding conforms to Payo's idea that the classroom atmosphere develops a relaxed style of communication. Teachers' behavior is a factor that influences performance, hence, teachers should see to it that they teach in a relaxed, non-threatening manner and communicate properly to the students. Manifesting assurance that students learn from a lesson, prioritizing whole class participation, and observing attendance in the various school activities were found to be moderately manifested as assessed by the teachers. These are reflected in the weighted means from 2.93 to 2.88 . Teachers need to be sure that their students are learning from them and thus should continuously ascertain maximum class participation. They must also see to it students are present in all academic and nonacademic activities, so students must be properly motivated to participate in these activities for their holistic growth. As Salandanan emphasized, teachers need to motivate their students to develop the ability and aspiration to learn. The teachers' assessment also revealed that taking into account a conducive learning environment, exemplifying leadership in the service, implementing flexible working environment, and measuring and composing feedback and report on students learning for parents' opportunity to get involved with students' progress were all moderately manifested, with weighted means ranging from 2.85 to 2.83 .

\section{B. Emotional Domain}

Expressing how one feels toward work and other academic and professional concerns cover the emotional domain, which also affects teacher engagement. Based on the assessment of the school heads, perceiving that a task is important and useful in the future was moderately manifested as seen in the highest weighted mean of 3.12. This implies that teachers need to appreciate more the task they are entrusted to do. They need to understand that this has a huge impact in the future and so they must maintain a certain level of appreciation to it. This emphasizes the importance of the teachers' positive attitude and disposition in teaching. Through this, they need would be able to sustain and provide meaningful classroom activities appropriate for the students, coupled with the proper values and morals. This is what Corpuz meant when she stated that teachers are professionals who are knowledgeable, skilled and value-laden. In addition, they must have internalized the edicts of the profession, and exhibit ethical and moral conduct at all times. Avoiding expressing themselves whenever the feel unpleasant emotions was assessed by school heads to be moderately manifested as reflected in the weighted mean of 2.86. This means that while they need to exercise caution and prudent, teachers should also learn to be expressive and honest with what they feel and do. At times, they have to learn to show genuine actions and behaviors. As revealed in the interview, teachers must be observant on how they use words and react in front of many people, especially when confronted with a situation that requires them to be professional. The composite mean of 2.99 indicates that teacher engagement is moderately manifested in terms of the emotional domain. This implies that teachers need to be given more opportunities to express their genuine feelings and emotions towards work and other matters related to the school in order for them to be fully engaged in their work. Based on the teachers' assessment, perceiving that a task is important and useful in the future was revealed to be moderately manifested as evident in the highest weighted mean of 3.11. This means that teachers should appreciate the tasks they do relative to how valuable these are in the future. They also have to ensure that they remain committed in the 
profession no matter how challenging it may seem. As Chang reiterated, teaching is a very challenging career and thus needs adequate preparation. Giving empathy towards students, ensuring an individual's sense of belongingness, and believing teaching as an ideal vocation for life were all moderately manifested as seen in the weighted means ranging from 3.07 to 3.01. This means that teachers should be compassionate with the needs of the students, and have to make sure that students feel at home and are part of the group. In addition, they need to believe that teaching is the most fulfilling profession. As Bauzon posited, effective teachers combine professionalism with care, understanding, fairness and kindness. They have to be passionate, enthusiastic, and motivated about teaching and learning. Teachers' assessment revealed that feeling confident about accomplishing goals in teaching, caring about problems of students in class, and feeling liked and respected by students were moderately manifested as seen in the weighted means ranging from 2.99 to 2.95 . Teachers need to feel confident and secured in the accomplishment of their daily goals and must be able to address students' problems. They also need to feel that they are liked and respected by the students and everyone in the school community. This is in line with Payos' contention that teaching requires well-rounded teachers who are confident and respectable professionals. Adapting DepEd's core values of being Maka-Diyos, Makatao, Maka-kalikasan at Maka-bansa, feeling excited and happy about teaching, creating a genuine smile regardless of the kind of day were all revealed to be moderately manifested as reflected in the weighted means ranging from 2.93 to 2.88 . This underscores the importance of teachers' adherence to the DepEd mandate at all times. In addition, they have to feel excited about teaching, and must maintain proper composure and disposition. As revealed in the FGD, teachers are happy persons who significantly contribute in the development of the students and in the attainment of school goals. Moreover, the teachers' assessment also revealed that projecting interest on a positive output and response from students, valuing relationships built at the workplace, and sustaining learning activities interesting, fun and enjoyable for learners were moderately manifested as reflected in the weighted means ranging from 2.85 to 2.83 . This means that teachers need to stay fulfilled and satisfied while in the teaching profession. They also need to provide more relevant student activities that promote effective learning. It was also revealed that avoiding expressing themselves when they feel unpleasant emotions was moderately manifested as reflected in the weighted mean of 2.81. This implies that teachers need to learn how to express their feelings and sentiments genuinely when needed. The composite mean 2.93 means that teacher engagement was moderately manifested in the emotional domain. This means that teachers should be more expressive and cognizant of the feelings they have towards work and other members of the school community in order for them to remain engaged.

\section{Sources of Burnout}

This study also analyzed the different factors that were believed to be sources of the teachers' burnout as a result of worry and exhaustion. This is an outcome of a gradual process of physical, emotional and psychological wear and tear.

It can be noted that the work overload issue ranked as the primary source of burnout in teaching. It means that teachers experience massive issues in teaching loads and assignment. This also means that their work assignment may not be properly noted, compensated, or recognized. As a response in the FGD, teachers claimed that they have difficulty in coping with this kind of situation, wherein there is a mismatch on the teaching load given to them and other work-related assigned by authorities. For instance, there are teachers who teach subjects that are not aligned to their area of specialization. They really find it difficult to find logic in this scenario, especially on how to make their students connect to ideas or concepts which they themselves struggle in absorbing as a result of out-of-field teaching. There are also teachers who do not feel their value in the field because of non-promotion even when they are qualified to fill the vacant position. According to some teachers, the practice of their school heads in giving assignment is sometimes unjust, which elicits conflict of interest. They even suggested that it is important for every teacher to feel valued and be provided with exposure to a post where they ought to be someday because teachers need professional support and encouragement. More so, for some school head and teacher respondents, the main cause of these is the lack of encouragement, social support and understanding for teachers. Noted to be the second in rank is absence of an awards and recognition system, which also adds to teachers' burnout. This just shows that in DepEd, especially in SHS, there is no systematic way of appreciating teachers' accomplishments and contributions. There are no monetary appropriations for their work and extra duties and responsibilities that they perform along with their basic task of teaching. This apparent lack of appreciation and recognition of their efforts cause burnout among them. Apart from a good salary increase, it was revealed during the FGD and interviews that they never receive anything else from the government that could be considered as a token of appreciation for their work. Teachers give their best to provide solutions to the needs of students and school community. They serve as parents, counselors, guardians and friends to their students. They even spend their own money especially in providing good classroom facilities to help the school. They exert efforts and provide great contributions to the other departments or agencies of the government. They do all of these while juggling several paper works, all of which affects their teaching performance. According to the respondents, it is obvious that teachers are always expected to do different tasks, especially relative to programs being implemented by government agencies like the Department of Health for the giving of vaccines, as well as the Local Government Unit for the 4P's or the Pantawid Pamilya Pilipino Program. Amidst all these, they feel unrecognized; despite all their sacrifices, they do not feel valued. They thirst recognition and reward which may make them feel happy and respected so they would be more persistent and enthusiastic to perform their tasks. 


\section{Conclusion}

This paper presented an overview on teaching engagement of senior high school teachers in Batangas province Philippines.

\section{References}

[1] A. Abrenica, "Burn Out Level of DLSU Faculty Members," in Behavioral Sciences Department Journal, vol. 10, pp. 30-40, 2015.
[2] D. J. Esguerra, "Deped Urged to lighten workloads following suicide reports," Philippine Daily Inquirer, August 27, 2018.

[3] A. A. Maque, "Correlates of Burnout and Teachers Burnout and Teachers Performance," Unpublished Dissertation, 2013.

[4] R. Tolentino, "Stress Management Strategies Among Notre Dame University Faculty and Administrators," Unpublished Dissertation, 2009. 